DOI: 10.20472/IAC.2018.044.016

\author{
ANTON GROBLER \\ University of South Africa, South Africa
}

\title{
SUPERVISORY TRUST TO BE EARNED - THE ROLE OF ETHICAL LEADERSHIP MEDIATED BY PERSON-ORGANISATIONAL FIT
}

\begin{abstract}
:
Background: The trust relationship between employees and their supervisors (called Supervisory trust) has a definite impact on employee behaviour and attitudes. Furthermore, various studies found that Ethical leadership impacts on Supervisory trust, but in different contexts, and often with homogeneous or limited samples. The interactionist construct of Person-organisational fit (P-O fit), consisting of a combination of Supplementary fit (indirect fit or value congruence) and Complementary fit (direct or person-job fit, as well as needs-supply fit) may, however, impact on the relationship between ethical leadership and supervisory trust. The unique permutations of these relationships are important not only for conceptualisation purposes, but also for intervention design to enhance the employees' trust in their supervisors; this would contribute to positive employee behaviour and attitudes.
\end{abstract}

Aim: The purpose of this study was to determine whether a relationship exists between Ethical leadership and Supervisory trust, with possible mediation by P-O fit.

Setting: The research was conducted with \pm 60 employees from each of 17 private sector and four public sector organisations in South Africa.

Method: This study utilised a positivist methodology based on an empirical approach, while using a cross-sectional design and quantitative analysis. The sample is relatively representative (in terms of race, gender and the South African work force), as it consisted of 60 employees from each of the 21 South African organisations that participated in the study, with 1260 respondents in total.

Results: Significant, positive relationships were found between Ethical leadership, P-O fit and Supervisory trust. Additionally, it was found that P-O fit partially mediates the relationship between Ethical leadership and Supervisory trust, confirming the proposed model.

Conclusion: A strong, positive relationship exists between Ethical leadership (consisting of Morality and fairness, Role clarification leadership and Power sharing leadership) and Supervisory trust, which is partially mediated by P-O fit (consisting of Supplementary fit and Complementary fit).

\section{Keywords:}

Ethical leadership; Person-organisational (P-O) fit, Supervisory trust

JEL Classification: D23 